\title{
Haematuria in rheumatoid arthritis: an association with mesangial glomerulonephritis*
}

\author{
L. D. HORDON,$^{1} \mathrm{~L}$. SELLARS,$^{2}$ A. R. MORLEY,$^{3} \mathrm{R}$. WILKINSON ${ }^{2}$ \\ M. THOMPSON ${ }^{1}$ AND I. D. GRIFFITHS ${ }^{1}$
}

From the Departments of ${ }^{1}$ Rheumatology, ${ }^{2}$ Nephrology, and ${ }^{3}$ Histopathology, Freeman Hospital, Newcastle upon Tyne

SUMMARY Twenty-four patients with rheumatoid arthritis and isolated haematuria were investigated for the cause of their haematuria. In 3 patients local urological disorders were identified, including a pelvicaliceal carcinoma. Renal biopsies were performed on the remaining 21 patients, and the most common abnormality found was a mild mesangial glomerulonephritis (71\%). Immunofluorescence and electron microscopy in these patients usually gave normal results. The lesions occurred independently of gold or D-penicillamine therapy and were not associated with impairment of glomerular function.

Renal involvement in rheumatoid arthritis is well recognised but is usually attributed to either the development of amyloidosis, adverse reactions to gold or penicillamine, analgesic nephropathy, or an interstitial nephritis with tubular dysfunction in patients with associated keratoconjunctivitis sicca. The presence of a specific renal lesion occurring in rheumatoid arthritis remains controversial. ${ }^{1}$ Postmortem studies have suggested the presence of both renal vasculitis and mild mesangial glomerulonephritis, ${ }^{2}$ and the latter finding has also been reported in a group of patients receiving gold therapy. ${ }^{3}$ This study is based on the clinicopathological findings in a group of 31 patients suffering from rheumatoid arthritis who were found to have recurrent, asymptomatic, microscopical haematuria occurring in the absence of urinary infection. Only a minority of these patients had had or were receiving either gold or penicillamine therapy, and the most common abnormality detected was that of a mild mesangial glomerulonephritis.

\section{Patients and methods}

Patients were included in the study on the basis of

Accepted for publication 4 August 1983.

* Presented to the Combined Heberden Society Meeting, Cambridge, in September 1982.

Correspondence to Dr I. D. Griffiths, Department of Rheumatology, Freeman Hospital, Freeman Road, Newcastle upon Tyne NE7 7DN. having classical or definite rheumatoid arthritis ${ }^{4}$ and recurrent microscopic haematuria on routine testing (Labstix, Ames Diagnostics). Patients with proteinuria $(>0.3 \mathrm{~g} / \mathrm{l}$ on routine testing) were excluded. Mid-stream urine specimens were cultured on all patients and those with urinary tract infections were excluded.

A total of 31 patients fulfilling the above criteria were identified during a 5-year period. Of these patients 3 who were receiving Myocrisin (sodium aurothiomalate) had resolution of the haematuria on discontinuing Myocrisin. Intravenous urograms (IVU), cystoscopies, and renal biopsies were not therefore performed on these patients. A further 3 patients, also receiving Myocrisin, had normal IVUs and cystoscopies. Urinary red cell casts were not present, and renal biopsy was not performed. These 3 patients have continued on Myocrisin with intermittent, asymptomatic haematuria, but without any deterioration in renal function or proteinuria. A further patient developed haematuria while receiving D-penicillamine. An IVU was normal, and the haematuria resolved on discontinuing D-penicillamine. No further investigations were undertaken.

This report concentrates on the remaining 24 patients in whom full urological and nephrological assessments were performed. In all patients urine samples were examined under high-power microscopy for granular and red cell casts. Serum creatinine, rheumatoid factor titres, and antinuclear factors were measured. Serum complement levels 
$\left(\mathrm{C} 3, \mathrm{C} 4, \mathrm{CH}_{50}\right)$ were measured at the time of renal biopsy in 17 patients.

IVUs were performed on all patients and, in the absence of urinary casts, cystoscopy. Renal biopsy was performed if no urological abnormality had been detected to account for the haematuria. Renal biopsies were assessed by one of us (A.R.M.) on light microscopy, and by immunofluorescence and electron microscopy where possible.

\section{Results}

\section{IVU ABNORMALITIES}

One patient, a 57-year-old female with a 7-month history of classical, rheumatoid arthritis was shown to have a filling defect in the renal pelvis. At surgery this was found to be a papillary uroepithelial carcinoma. Another patient had a small scarred kidney, compatible with the appearance of chronic pyelonephritis. Urinary cultures on this patient were persistently sterile, but at cystoscopy she was found to have evidence of a chronic cystitis. None of the patients had IVU evidence of analgesic nephropathy.

\section{CYSTOSCOPY}

Cystoscopy was performed on 14 patients. Abnormalities were detected in only 2. In 1 patient, described above, there was evidence of a chronic cystitis. The other patient gave a history of frank, macroscopic haematuria which had occurred while receiving a variety of nonsteroidal anti-inflammatory agents and which resolved when the antiinflammatory drugs were discontinued. Two cystoscopies performed in the absence of macroscopic haematuria were normal, but a further cystoscopy performed during an episode of haematuria showed a frank haemorrhagic cystitis. Neither of these patients had received gold, D-penicillamine, or cytotoxic agents.

\section{RENAL HIST OLOGY}

Percutaneous renal biopsies were performed on 21 patients, all of whom had normal IVUs. Their mean age was 50 years (range 41 to 70 years); mean duration of rheumatoid arthritis 9 years (range 6 months to 25 years); and the female to male ratio was 2 to 1 . The clinical and serological details of these patients are given in Table 1.

Two patients gave positive tests for antinuclear factor, but DNA binding levels were within the normal range. Both patients had positive rheumatoid factor tests and an erosive, peripheral arthropathy with nodules. There were no clinical features to suggest that they had systemic lupus erythematosus. Complement $\left(\mathrm{C} 3, \mathrm{C} 4\right.$, and $\left.\mathrm{CH}_{50}\right)$ values were available at the time of biopsy in 17 patients and were normal or elevated in all cases.

Light microscopy. The findings on renal biopsy are shown in Table 2. The most common abnormality was a mild, mesangial glomerulonephritis present in 15 patients $(71 \%)$ (Fig. 1). None of these patients had an increased serum creatinine. Two of the patients were receiving D-penicillamine; one had had 100 to $200 \mathrm{mg}$ daily for 12 months, the other 125 to $250 \mathrm{mg}$ daily for 5 months. A third case had received a total dose of $30 \mathrm{mg}$ of Myocrisin. All were receiving nonsteroidal anti-inflammatory drugs, and one patient was receiving hydroxychloroquine.

Table 1 Summary of clinical features of 21 patients undergoing renal biopsy for haematuria

\begin{tabular}{lllllll}
\hline $\begin{array}{l}\text { Extra-articular } \\
\text { features and } \\
\text { serological findings }\end{array}$ & Nodules & Vasculitis & $\begin{array}{l}\text { Felty's } \\
\text { syndrome }\end{array}$ & $\begin{array}{l}\text { Kerato- } \\
\text { conjunctivitis } \\
\text { sicca }\end{array}$ & $\begin{array}{l}\text { Positive } \\
\text { rheumatoid } \\
\text { factor }\end{array}$ & $\begin{array}{l}\text { Positive } \\
\text { antinuclear } \\
\text { factor }\end{array}$ \\
\hline Incidence (\%) & 38 & 19 & 11 & 32 & 86 & 9 \\
\hline
\end{tabular}

Table 2 Summary of renal biopsy findings on light microscopy in 21 patients

\begin{tabular}{|c|c|c|c|c|}
\hline Histological features & Total no. & $\begin{array}{l}\text { No. receiving } \\
\text { gold/ } \\
\text { penicillamine }\end{array}$ & $\begin{array}{l}\text { No. with } \\
\text { elevated serum } \\
\text { creatinine }\end{array}$ & $\begin{array}{l}\text { No. with red } \\
\text { cell or granular } \\
\text { casts in urine }\end{array}$ \\
\hline Mesangial glomerulonephritis & 15 & 3 & & 5 \\
\hline Membranous glomerulonephritis & 1 & 1 & & 1 \\
\hline Focal proliferative glomerulonephritis & 1 & & 1 & 1 \\
\hline Interstitial fibrosis & 1 & & & \\
\hline Arteriosclerotic ischaemic changes & 2 & & 1 & 1 \\
\hline Normal & 1 & 1 & & \\
\hline
\end{tabular}




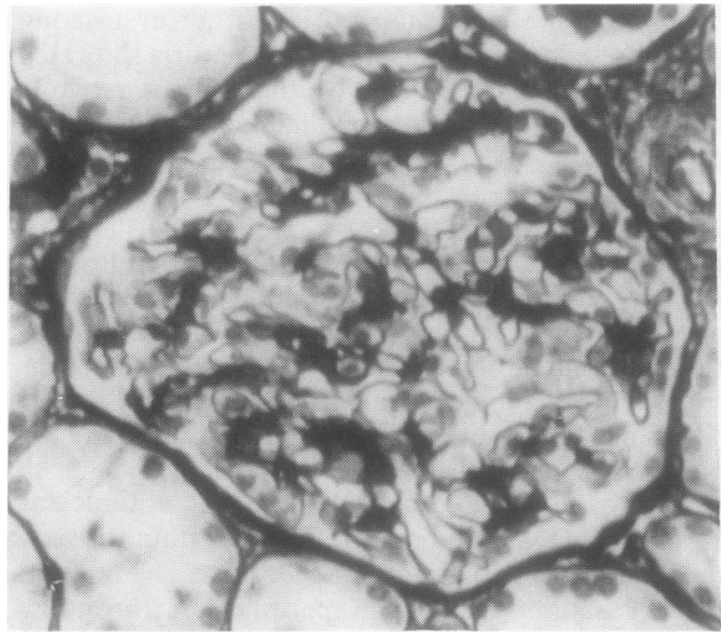

Fig. 1 Glomerulus showing a mild increase in mesangial matrix. (Periodic acid silver methenamine, $\times 250$ ).

The patient who showed a membranous glomerulonephritis on renal biopsy did not have proteinuria. At the time of biopsy the patient was receiving penicillamine $50 \mathrm{mg}$ daily for 4 weeks but had previously received a course of Myocrisin (total 1150 $\mathrm{mg}$ ), which had been discontinued 6 months before biopsy because of thrombocytopenia.

The patient with interstitial fibrosis had keratoconjunctivitis sicca and nodular rheumatoid arthritis. There was no history of analgesic abuse.

One patient developed persistent haematuria after 3 doses (225 mg total) of penicillamine. She had a normal renal biopsy and cystoscopic appearances were normal; the cause of her haematuria was not apparent.

Serum creatinine levels were elevated in only 2 patients. One male patient had a focal glomerulonephritis with crescents (Fig. 2). The creatinine at time of biopsy was $180 \mu \mathrm{mol} / 1$ and had not increased further in the 3 years since biopsy. This patient had classical, erosive, nodular, seropositive rheumatoid arthritis, with an associated digital and cutaneous vasculitis, peripheral neuropathy, and mononeuritis. The other patient, a miner, with pneumoconiosis and Caplan's syndrome, had severe arteriosclerotic, ischaemic changes on biopsy. At presentation he was normotensive, with a serum creatinine of $141 \mu \mathrm{mol} / 1$. He later became severely hypertensive, and his renal function rapidly deteriorated, the serum creatinine rising to $600 \mu \mathrm{mol} / 118$ months after biopsy.

Electron microscopy. Electron microscopy was done on 7 of the 14 patients with mesangial

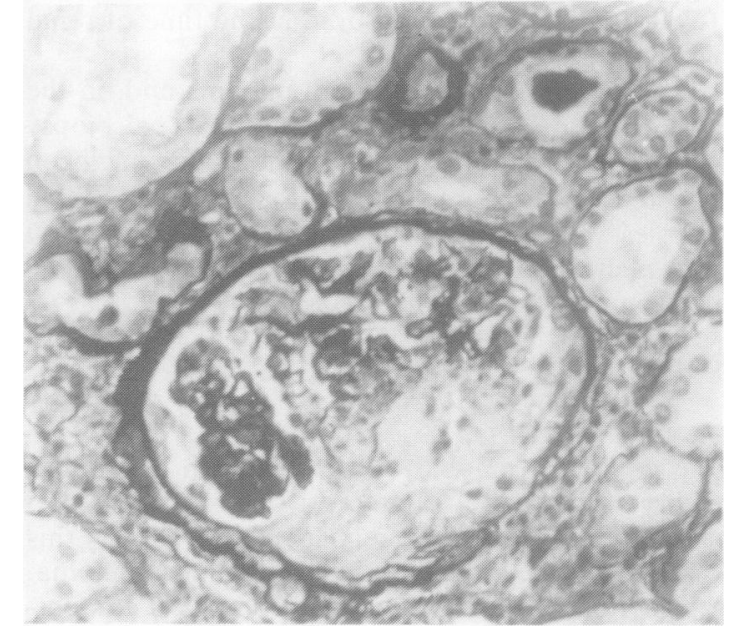

Fig. 2 Glomerulus showing a fibrosing crescent. (Periodic acid silver methenamine, $\times 250$ ).

glomerulonephritis. Electron dense deposits were seen in only one of these 7 patients and were present on the subendothelial basement membrane.

Immunofluorescence. Immunofluorescence for $\operatorname{IgG}, \mathrm{A}, \mathrm{M}, \mathrm{C} 3$, and fibrin was tested in 10 of the 14 patients with mesangial glomerulonephritis. No significant immunofluorescence could be detected in 7. Of the remainder 2 had granular deposits in the mesangium; these were IgM in one and IgG, A, M, and $\mathrm{C} 3$ in the other. The final patient had tubular casts containing $\operatorname{IgA}$ and fibrin.

\section{Discussion}

The finding that one of our patients had a surgically treatable renal pelvicaliceal carcinoma obviously stresses the need for complete evaluation of any patient with haematuria. However, the most common abnormality detected in the present series was in renal histology, in particular, a mild mesangial glomerulonephritis. Such changes have recently been reported in a post-mortem series of 76 rheumatoid patients, where mesangial proliferation was found in $38 \%$ of the patients compared with $15 \%$ of the controls. ${ }^{2}$ Similar histological abnormalities have also been detected in renal biopsy specimens from patients who developed proteinuria or haematuria while receiving gold, ${ }^{3}$ and the renal abnormalities were attributed to Myocrisin therapy. Such an explanation would seem unlikely on the basis of our findings, as only 3 of the 14 patients with mesangial glomerulonephritis were receiving either gold or penicillamine therapy. Whether the mesangial 
changes are casually or causally related to the haematuria is difficult to establish from the present series, as it was considered unethical to take biopsy specimens from patients with rheumatoid arthritis who did not have urinary abnormalities. It would seem probable, however, that the renal changes are related to the haematuria, as similar findings on renal biopsy have also been reported in nonrheumatoid patients with asymptomatic haematuria. ${ }^{5}$

Previous series describing the findings on renal biopsy from unselected rheumatoid patients have usually failed to detect any evidence of mesangial proliferation, ${ }^{6-8}$ though a localised 'glomerulitis' was detected in over half of the 20 patients studied by Pasternack et al. ${ }^{9}$ On balance, however, present evidence suggests that a mesangial glomerulonephritis is not a common finding on renal biopsy in unselected rheumatoid patients, and further supports the view that the changes observed in our series probably are related to the persistent haematuria.

The aetiology of the mesangial glomerulonephritis is uncertain. While this may be on the basis of circulating immune complexes, the relative infrequency of both immunoglobulin deposition and electron dense deposits is in marked contrast with the findings in systemic lupus erythematosus. ${ }^{10}$ It is possible that we have merely observed a fortuitous association of haematuria, which may be present in $1 \%$ of the population, ${ }^{11}$ and rheumatoid arthritis. However, this seems unlikely, as we did not encounter any cases of haematuria in patients who had osteoarthritis. It is also unlikely that the haematuria can be explained as a chance finding occurring sporadically, and therefore likely to be detected when repetitive urine tests are done, as this is only routinely undertaken in patients receiving second-line therapy, and such patients represented only $25 \%$ of those biopsied.

Impairment of renal function does not appear to be a clinically important aspect of mesangial glomerulonephritis in the rheumatoid patient, but prolonged follow-up of these patients is obviously required. Only 2 patients in the present series had impaired renal function. In one this was thought to be incidental to his rheumatoid disease, and the other patient, with a focal proliferative glomerulonephritis, had an extensive, cutaneous vasculitis and neuropathy, suggesting that he may have had polyarteritis nodosa in association with his seropositive rheumatoid arthritis.

The presence of urinary red cell or granular casts was noted in 9 of the 21 patients undergoing renal biopsy but proved to be an unreliable indicator of the histological severity of renal lesion. The introduction of phase contrast microscopy of urine may, however, prove to be a more reliable indicator of both the origin of red cells and their clinical significance. ${ }^{12}$

The absence of amyloidosis in these patients is undoubtedly due to the fact that patients with proteinuria were excluded, but it is of interest that no cases of analgesic nephropathy were encountered. This probably reflects both the removal of phenacetin from analgesic preparations and the more cautious use of analgesics in rheumatoid patients. We also failed to detect any cases of renal vasculitis, a condition which has previously been reported in post-mortem studies. ${ }^{13}$ This may reflect the sampling size of percutaneous renal biopsy specimens, but other series reporting on renal biopsies in rheumatoid patients have also failed to detect histological evidence of renal vasculitis. ${ }^{6-9}$

It would seem therefore that, while surgical causes of haematuria have to be sought in patients with rheumatoid arthritis, the most common abnormality is found on renal biopsy-in particular, a mild, mesangial glomerulonephritis. This does not appear to have an adverse effect on renal function or to be associated with second-line therapy.

\section{References}

1 Burry H. Renal disorders in rheumatoid arthritis. Rheumatol Phys Med 1971; 11: 2-9.

2 Ramirez G, Lambert R, Bloomer H A. Renal pathology in rheumatoid arthritis. Nephron 1981; 2: 124-6.

3 Blackwell M R, Hall C L, Tribe C R, Bacon P A. Gold induced nephropathy. Ann Rheum Dis 1981; 40: 525.

4 Ropes M W, Bennett G A, Cobb S, Jacox R, Jessar R A. Revision of the diagnostic criteria for rheumatoid arthritis. Ann Rheum Dis 1959; 18: 49-54.

5 Sinniah R, Pwee H S, Lim C H. Glomerular lesions in asymptomatic microscopic haematuria discovered on routine medical examination. Clin Nephrol 1976; 5: 216-28.

6 Pollak V E, Pirani C L, Steck I E, Kark R M. The kidney in rheumatoid arthritis: studies by renal biopsy. Arthritis Rheum 1962; 5: 1-9.

7 Brun C, Steen Olsen T, Raashou F, Sorenson A W S. Renal biopsy in rheumatoid arthritis. Nephron 1965; 2: 65-81.

8 Camp A V, Mowat A G, Fletcher W.B, Dunnill M S, McIver A G. A study of renal disease in rheumatoid arthritis. Ann Rheum Dis 1973; 32: 278-9.

9 Pasternack A, Wegelius O, Makișara P. Renal biopsy in rheumatoid arthritis. Acta Med Scand 1967; 182: 591-6.

10 Ginzler E M, Blumenthal D R. Renal involvement in SLE: clinical and pathological spectrum. In: Bacon P A, Hadler N W, eds. The kidney and rheumatic disease. London, Boston, Wellington, Durban, Toronto: Butterworth, 1982.

11 Kincaid-Smith P. Haematuria and exercise-related haematuria. Br Med J 1982; 285: 1595-6.

12 Birch D F, Fairley K F. Haematuria: glomerular or nonglomerular? Lancet 1979; ii: 845-6.

13 Lawson A A H, MacClean N. Renal disease and drug therapy in rheumatoid arthritis. Ann Rheum Dis 1966; 25 : 441-9. 